\title{
Hospital admissions before the age of 2 years in Western Australia
}

\author{
Anne W Read, John Gibbins, Fiona J Stanley, Patricia Morich
}

\begin{abstract}
A linked data file of birth records and hospital admissions was used to investigate inpatient hospital morbidity before 2 years of age for all non-Aboriginal and Aboriginal children born in Western Australia in 1986. Of the non-Aboriginal children, $31 \cdot 8 \%$ were admitted to hospital at least once before the age of 2 years, with an overall admission rate of 526/1000 live births; the corresponding figures for Aboriginal children were $68 \cdot 7 \%$ and 2797. The mean number of days in hospital for each non-Aboriginal child admitted was $7 \cdot 4$, and $26 \cdot 5$ for Aboriginal children. Of the total cohort, $21 \%$ of non-Aboriginal and $20 \%$ of Aboriginal children were admitted only once, and $4 \%$ of nonAboriginal and $36 \%$ of Aboriginal children were admitted at least three times; $23 \%$ of non-Aboriginal and $24 \%$ of Aboriginal children were admitted for only one major disease category, and $1 \%$ of nonAboriginal and $16 \%$ of Aboriginal children were in at least four categories. The highest admission rates and highest percentages of the cohort admitted were for gastrointestinal and respiratory diseases and social admissions. These results illustrate the importance for both descriptive and analytical research of relating admissions to hospital for the total population to the individual child, and of using clinically relevant disease classifications.
\end{abstract}

(Arch Dis Child 1994; 70: 205-210)

Most health information systems in developed countries are based on episodes and are not linked to individual subjects. The Maternal and Child Health Research Data Base of Western Australia is the only database in Australia where this linkage to individual children is routinely carried out for the total state population. For all children born in Western Australia from 1980 onwards, we have linked data relating to their antenatal, perinatal, and postnatal histories, together with hospital admissions up to the age of 6 years. Similar work has been carried out with the Oxford record linkage study ${ }^{12}$ in the United Kingdom and some results are also available from smaller, specially linked data sets. ${ }^{34}$ In this work we used the linked data to investigate hospital inpatient morbidity up to the age of 2 years for non-Aboriginal and Aboriginal children born in Western Australia in 1986.

\section{Methods}

The Maternal and Child Health Research Data Base is based on the Western Australia midwives' notification of birth forms together with birth and death registrations from the Western Australia registrar general. The midwives' notifications are legal documents completed by the attending midwife for every birth in Western Australia, including stillbirths of at least 20 weeks' gestation or $400 \mathrm{~g}$ birth weight. ${ }^{5}$ To these records we have added data from the Western Australia Hospital Morbidity Data Collection by linking hospital discharge records to individual birth records for all children born in Western Australia from 1980 onwards. The Western Australia Hospital Morbidity Data Collection contains discharge data for every public and private hospital in Western Australia, including the major diagnosis, which is the condition best characterising the period of stay in hospital, and up to 15 other problems are also coded. All diagnoses are coded according to the four digit categories of the International Classification of Diseases (ICD9). ${ }^{6}$

For this paper we used linked hospital discharge data for the first two years of life (including neonatal admissions) for all children born in Western Australia in 1986. The overall linkage rates for hospital discharge data to birth records were $96 \%$ for nonAboriginal and $88 \%$ for Aboriginal children. For certain morbidities in which we have a particular interest (such as lower respiratory tract illness and perinatal conditions) we have linked almost $100 \%$ of the discharge records for the two racial groups by going back to the individual hospitals. Children admitted to hospitals in Western Australia but known to have been born outside the state were excluded from the study. Children born in Western Australia but subsequently admitted to hospitals outside the state are included in the cohort but not in the hospital admissions data. As this study includes only children up to the age of 2 years, this number is likely to be small. In a separate longitudinal study in Western Australia of children whose mothers were enrolled during pregnancy, about $3 \%$ of children had moved out of the state to live elsewhere between birth and the age of 2 years (W MacDonald, personal communication).

The ICD9 morbidity categories were classified in two ways using the major diagnosis for each admission: firstly, in accordance with the basic tabulation list $^{6}$ (to enable comparison with other studies) and secondly, in clinically relevant categories developed for this study. These categories were agreed with practising 
Table 1 Hospital admissions up to the age of 2 years in diagnostic categories (principal diagnosis only) of the basic tabulation list of ICD9: Western Australia 1986 birth cohort. Excludes 62 records for 29 children of unknown race

\begin{tabular}{|c|c|c|c|c|}
\hline \multirow[b]{2}{*}{ ICD9 category } & \multicolumn{2}{|c|}{ Non-Aboriginal $(n=22456)$} & \multicolumn{2}{|c|}{ Aboriginal $(n=1228)$} \\
\hline & $\begin{array}{l}\text { No (\%) of } \\
\text { admissions }\end{array}$ & $\begin{array}{l}\text { Rate/1000 } \\
\text { live births }\end{array}$ & $\begin{array}{l}\text { No (\%) of } \\
\text { admissions }\end{array}$ & $\begin{array}{l}\text { Rate/1000 } \\
\text { live births }\end{array}$ \\
\hline Perinatal conditions & $1830(15 \cdot 5)$ & 81 & $186(5 \cdot 4)$ & 151 \\
\hline 'Other' reasons & $1794(15 \cdot 2)$ & 80 & $455(13 \cdot 2)$ & 371 \\
\hline Ill defined conditions & $1356(11 \cdot 5)$ & 60 & $442(12.9)$ & 360 \\
\hline Lower respiratory tract diseases & $1255(10 \cdot 6)$ & 56 & $788(22.9)$ & 642 \\
\hline Upper respiratory tract diseases & $1085(9 \cdot 2)$ & 48 & $266(7 \cdot 7)$ & 217 \\
\hline Congenital anomalies & $783(6 \cdot 6)$ & 35 & $70(2 \cdot 0)$ & 57 \\
\hline Oral and digestive diseases & $682(5 \cdot 8)$ & 30 & $133(3.9)$ & 108 \\
\hline Intestinal infections & $558(4 \cdot 7)$ & 25 & $415(12 \cdot 1)$ & 338 \\
\hline Injuries & $506(4 \cdot 3)$ & 23 & $66(1.9)$ & 54 \\
\hline Ear diseases & $415(3.5)$ & 18 & $112(3 \cdot 3)$ & 91 \\
\hline Eye diseases & $303(2 \cdot 6)$ & 13 & $46(1 \cdot 3)$ & 37 \\
\hline Other infections and parasites & $300(2 \cdot 5)$ & 13 & $140(4 \cdot 1)$ & 114 \\
\hline Mental and nervous diseases & $184(1 \cdot 6)$ & 8 & $31(0.9)$ & 25 \\
\hline Skin diseases & $149(1 \cdot 3)$ & 7 & $133(3.9)$ & 108 \\
\hline Diseases of genitals & $152(1 \cdot 3)$ & 7 & $12(0 \cdot 3)$ & 10 \\
\hline Poisonings & $155(1.3)$ & 7 & $13(0 \cdot 4)$ & 11 \\
\hline Neoplasms & $111(0.9)$ & 5 & $14(0.4)$ & 11 \\
\hline Urinary diseases & $98(0 \cdot 8)$ & 4 & $57(1 \cdot 7)$ & 46 \\
\hline Musculoskeletal diseases & $47(0 \cdot 4)$ & 2 & $9(0 \cdot 3)$ & 7 \\
\hline \multirow{2}{*}{$\begin{array}{l}\text { Endocrine, metabolic, and blood } \\
\text { disorders }\end{array}$} & & & & \\
\hline & $56(0 \cdot 5)$ & 2 & $47(1 \cdot 4)$ & 38 \\
\hline Total admissions & $11819(100 \cdot 0)$ & 526 & $3435(100 \cdot 0)$ & 2797 \\
\hline Total children in cohort admitted & $7133(31 \cdot 8)$ & & $844(68 \cdot 7)$ & \\
\hline
\end{tabular}

paediatricians after studying the complete list of morbidities experienced by the children. Whereas the basic tabulation list is primarily a statistical classification based on causes of death and the aetiology of disease, our categories represent the manifestation of disease, and comprise groups of morbidities requiring a similar clinical approach. Except for table 1, the paper is based on the clinically relevant categories which are summarised in the appendix. For each category we calculated by race the following: the number and percentage of admissions and the admission rate per 1000 live births; the number and percentage of individual children admitted and the percentage of the cohort admitted; the mean length of hospital stay for each admission; and the total number of days in hospital per 1000 live births. We also calculated the frequency of hospital admission and the number of different major disease categories experienced by individual children. As this is a descriptive study, based on vital data for the total population, statistical analyses were not performed. The non-Aboriginal

Table 2 Hospital admissions up to the age of 2 years in clinically relevant diagnostic categories (principal diagnosis only) according to Appendix: Western Australia 1986 birth cohort. Excludes 62 records for 29 children of unknown race

\begin{tabular}{|c|c|c|c|c|}
\hline \multirow[b]{2}{*}{ Diagnostic category } & \multicolumn{2}{|c|}{ Non-Aboriginal $(n=22456)$} & \multicolumn{2}{|c|}{ Aboriginal $(n=1228)$} \\
\hline & $\begin{array}{l}\text { No (\%) of } \\
\text { admissions }\end{array}$ & $\begin{array}{l}\text { Rate/1000 } \\
\text { live births }\end{array}$ & $\begin{array}{l}\text { No (\%) of } \\
\text { admissions }\end{array}$ & $\begin{array}{l}\text { Rate/1000 } \\
\text { live births }\end{array}$ \\
\hline $\begin{array}{l}\text { Upper respiratory tract diseases } \\
\text { Gastrointestinal diseases } \\
\text { Lower respiratory tract diseases } \\
\text { Social admissions (healthy children) } \\
\text { Congenital anomalies } \\
\text { Perinatal conditions } \\
\text { Trauma, accidents, poisonings } \\
\text { 'Other' infectious diseases } \\
\text { Haematology/oncology } \\
\text { 'Other' problems } \\
\text { Neurology } \\
\text { Routine circumcision } \\
\text { Eye disorders } \\
\text { Renal problems } \\
\text { Vaccine preventable diseases } \\
\text { Mental disorders } \\
\text { Endocrine/genetic diseases }\end{array}$ & $\begin{array}{l}1862(15 \cdot 8) \\
1404(11 \cdot 9) \\
1357(11 \cdot 5) \\
1286(10 \cdot 9) \\
1182(10 \cdot 0) \\
982(8 \cdot 3) \\
715(6 \cdot 0) \\
598(5 \cdot 1) \\
557(4 \cdot 7) \\
564(4 \cdot 8) \\
492(4 \cdot 2) \\
314(2 \cdot 7) \\
212(1 \cdot 8) \\
105(0 \cdot 9) \\
64(0 \cdot 5) \\
78(0 \cdot 7) \\
47(0 \cdot 4)\end{array}$ & $\begin{array}{r}83 \\
63 \\
60 \\
57 \\
53 \\
44 \\
32 \\
27 \\
25 \\
25 \\
22 \\
14 \\
9 \\
5 \\
3 \\
3 \\
2\end{array}$ & $\begin{array}{r}658(19 \cdot 2) \\
819(23 \cdot 8) \\
559(16 \cdot 3) \\
415(12 \cdot 1) \\
81(2 \cdot 4) \\
128(3 \cdot 7) \\
98(2 \cdot 9) \\
320(9 \cdot 3) \\
34(1 \cdot 0) \\
160(4 \cdot 7) \\
58(1 \cdot 7) \\
3(0 \cdot 1) \\
3(0 \cdot 1) \\
70(2 \cdot 0) \\
12(0 \cdot 3) \\
3(0 \cdot 1) \\
14(0 \cdot 4)\end{array}$ & $\begin{array}{r}536 \\
667 \\
455 \\
338 \\
66 \\
104 \\
80 \\
261 \\
28 \\
130 \\
47 \\
2 \\
2 \\
57 \\
10 \\
2 \\
11\end{array}$ \\
\hline $\begin{array}{l}\text { Total admissions } \\
\text { Total children in cohort admitted }\end{array}$ & $\begin{array}{c}11819(100 \cdot 0) \\
7133(31 \cdot 8)\end{array}$ & 526 & $\begin{array}{l}3435(100 \cdot 0) \\
844(68 \cdot 7)\end{array}$ & 2797 \\
\hline
\end{tabular}

group comprised $94 \%$ white children and $6 \%$ 'other' races; the latter were mostly of Asian descent. Sixty two hospital records for 29 children of unknown race were excluded from the analysis.

\section{Results}

Table 1 gives hospital admissions in the diagnostic categories of the ICD9 basic tabulation list. The number of admissions and the percentage of the total in each category are shown, together with the rate per 1000 liveborn children in the cohort. Of the total cohort, $31 \cdot 8 \%$ of the non-Aboriginal children and $68.7 \%$ of the Aboriginal children had been admitted to hospital at least once in the first two years of life, with an overall admission rate of 526/1000 live births for non-Aboriginal and 2797/1000 live births for Aboriginal children. Rates in all morbidity categories were higher for Aboriginal children.

Table 2 shows hospital admissions in clinically relevant categories as summarised in the appendix. The four highest rates for both non-Aboriginal and Aboriginal children were for gastrointestinal diseases, upper and lower respiratory tract diseases, and social admissions. Differences between tables 1 and 2 include: (a) higher rates for gastrointestinal diseases (table 2) than for intestinal infections (table 1); (b) higher rates for upper respiratory tract diseases in table 2 than in table 1 ; (c) lower rates for lower respiratory tract diseases for Aboriginal infants in table 2 than in table 1; and (d) lower rates for perinatal disorders in table 2 than table 1.

Comparison of the two categorisations showed that: (a) the increased rate for gastrointestinal diseases in table 2 was mostly due to the transfer of disorders such as failure to thrive, which in table 1 had been included in the category of 'ill defined conditions'; (b) upper respiratory tract disease in table 2 included otitis media and 'other diseases of respiratory system, not elsewhere classified', whereas in table 1 the former was in ear diseases and the latter in lower respiratory tract diseases; (c) lower respiratory tract diseases in table 2 do not include other diseases of respiratory system, not elsewhere classified; and (d) perinatal disorders in table 2 exclude disorders which have been classified as lower respiratory tract diseases (such as bronchopulmonary dysplasia) and infections (which have been classified as 'other' infectious diseases).

Using the basic tabulation list ${ }^{6}$ it is difficult to document the group of healthy children who were admitted for social reasons as they are in a broad category which also includes children admitted for medical care and treatment. In table 1 these children are included in the category 'other' reasons, whereas in our classification (table 2) they are in the category of social admissions (healthy children). This latter category excludes children who had an elective procedure (such as circumcision) and those who were admitted for examinations or observations, or both. Our clinically relevant classification also allows for the documentation 
Table 3 Children admitted to hospital up to the age of 2 years in clinically relevant diagnostic categories (principal diagnosis only) according to Appendix: Western Australia 1986 birth cohort. Excludes 62 records for 29 children of unknown race

\begin{tabular}{|c|c|c|c|c|c|c|}
\hline \multirow[b]{2}{*}{ Diagnostic category ${ }^{\star}$} & \multicolumn{3}{|c|}{ Non-Aboriginal $(n=22456)$} & \multicolumn{3}{|c|}{ Aboriginal $(n=1228)$} \\
\hline & $\begin{array}{l}\text { No of } \\
\text { children } \\
\text { admitted }\end{array}$ & $\begin{array}{l}\% \text { Of } \\
\text { those } \\
\text { admitted }\end{array}$ & $\begin{array}{l}\% \text { Of } \\
\text { cohort } \\
\text { d admitted }\end{array}$ & $\begin{array}{l}\text { No of } \\
\text { children } \\
\text { admitted }\end{array}$ & $\begin{array}{l}\% \text { Of } \\
\text { those } \\
\text { admitted }\end{array}$ & $\begin{array}{c}\% \text { Of } \\
\text { cohort } \\
\text { d admitted }\end{array}$ \\
\hline Upper respiratory tract diseases & 1443 & $20 \cdot 2$ & $6 \cdot 4$ & 330 & $39 \cdot 1$ & $26 \cdot 9$ \\
\hline Gastrointestinal diseases & 1237 & 15.9 & $5 \cdot 1$ & 398 & $47 \cdot 2$ & $32 \cdot 4$ \\
\hline Lower respiratory tract diseases & 1013 & $14 \cdot 2$ & $4 \cdot 5$ & 296 & $35 \cdot 1$ & $24 \cdot 1$ \\
\hline Social admissions (healthy children) & 1144 & $16 \cdot 0$ & $5 \cdot 1$ & 294 & $34 \cdot 8$ & 23.9 \\
\hline Congenital anomalies & 881 & $12 \cdot 4$ & 3.9 & 43 & $5 \cdot 1$ & 3.5 \\
\hline Perinatal conditions & 905 & $12 \cdot 7$ & $4 \cdot 0$ & 112 & $13 \cdot 3$ & $9 \cdot 1$ \\
\hline Trauma, accidents, poisonings & 668 & $9 \cdot 4$ & $3 \cdot 0$ & 82 & $9 \cdot 7$ & $6 \cdot 7$ \\
\hline 'Other' infectious diseases & 568 & $8 \cdot 0$ & $2 \cdot 5$ & 232 & $27 \cdot 5$ & $18 \cdot 9$ \\
\hline Haematology/oncology & 482 & $6 \cdot 8$ & $2 \cdot 1$ & 21 & $2 \cdot 5$ & $1 \cdot 7$ \\
\hline 'Other' problems & 532 & $7 \cdot 5$ & $2 \cdot 4$ & 127 & $15 \cdot 0$ & $10 \cdot 3$ \\
\hline Neurology & 371 & $5 \cdot 2$ & $1 \cdot 7$ & 35 & $4 \cdot 1$ & $2 \cdot 9$ \\
\hline Routine circumcision & 309 & $4 \cdot 3$ & $1 \cdot 4$ & 2 & $0 \cdot 2$ & $0 \cdot 2$ \\
\hline Eye conditions & 177 & $2 \cdot 5$ & $0 \cdot 8$ & 2 & $0 \cdot 2$ & $0 \cdot 2$ \\
\hline Renal problems & 81 & $1 \cdot 1$ & 0.4 & 53 & $6 \cdot 3$ & $4 \cdot 3$ \\
\hline Vaccine preventable diseases & 61 & 0.9 & $0 \cdot 3$ & 8 & 0.9 & 0.7 \\
\hline Mental disorders & 73 & $1 \cdot 0$ & $0 \cdot 3$ & 3 & 0.4 & $0 \cdot 2$ \\
\hline Endocrine/genetic diseases & 33 & 0.5 & $0 \cdot 1$ & 13 & 1.5 & $1 \cdot 1$ \\
\hline Total children in cohort admitted & 7133 & & $31 \cdot 8$ & 844 & & $68 \cdot 7$ \\
\hline
\end{tabular}

^Each child can be in more than one category.

of diseases which can be prevented by vaccination as a separate category and shows a low admission rate for Aboriginal and nonAboriginal children for these morbidities compared with that for other infectious diseases.

Table 3 shows numbers and percentages of individual children admitted to hospital in clinically relevant categories. Categories are not mutually exclusive as each child could be admitted in one, several, or all categories. This table shows the numbers of individual children who had the admission rates shown in table 2. For example, if we consider upper respiratory tract diseases for non-Aboriginal children, 1443 children had 1862 admissions, giving an admission rate of $83 / 1000$ live births experienced by $6.4 \%$ of the cohort. Conditions with the highest percentages of individual children admitted were the same four as those noted in table 2, with about $4-6 \%$ of the non-Aboriginal population and $24-32 \%$ of the Aboriginal population being admitted for each of these conditions.

Table 4 indicates the duration of the admission to hospital. For each 1000 live

Table 4 Days spent in hospital up to the age of 2 years for each diagnostic category (principal diagnosis as classified in Appendix): Western Australia 1986 birth cohort. Excludes 62 records for 29 children of unknown race

\begin{tabular}{|c|c|c|c|c|c|c|}
\hline \multirow[b]{2}{*}{ Diagnostic category } & \multicolumn{3}{|c|}{ Non-Aboriginal $(n=22456)$} & \multicolumn{3}{|c|}{ Aboriginal $(n=1228)$} \\
\hline & $\begin{array}{l}\text { Total } \\
\text { days }\end{array}$ & $\begin{array}{l}\text { Mean } \\
\text { No of } \\
\text { days per } \\
\text { admission }\end{array}$ & $\begin{array}{l}\text { Total No } \\
\text { of days } \\
\text { per } 1000 \\
\text { live births }\end{array}$ & $\begin{array}{l}\text { Total } \\
\text { days }\end{array}$ & $\begin{array}{l}\text { Mean } \\
\text { No of } \\
\text { days per } \\
\text { admission }\end{array}$ & $\begin{array}{l}\text { Total No } \\
\text { of days } \\
\text { per } 1000 \\
\text { live births }\end{array}$ \\
\hline $\begin{array}{l}\text { Upper respiratory diseases } \\
\text { Gastrointestinal diseases } \\
\text { Lower respiratory diseases } \\
\text { Social admissions (healthy }\end{array}$ & $\begin{array}{l}4202 \\
4664 \\
5239\end{array}$ & $\begin{array}{l}2 \cdot 3 \\
3 \cdot 3 \\
3 \cdot 9\end{array}$ & $\begin{array}{l}187 \\
208 \\
233\end{array}$ & $\begin{array}{l}3060 \\
6387 \\
3443\end{array}$ & $\begin{array}{l}4 \cdot 7 \\
7 \cdot 8 \\
6 \cdot 2\end{array}$ & $\begin{array}{l}2492 \\
5201 \\
2804\end{array}$ \\
\hline children) & 4391 & $3 \cdot 4$ & 196 & 1784 & $4 \cdot 3$ & 1453 \\
\hline Congenital anomalies & 5430 & $4 \cdot 6$ & 242 & 7433 & $9 \cdot 2$ & 605 \\
\hline Perinatal conditions & 16966 & $17 \cdot 3$ & 756 & 2266 & $17 \cdot 7$ & 1845 \\
\hline Trauma, accidents, poisonings & 1846 & $2 \cdot 6$ & 82 & 576 & $4 \cdot 2$ & 469 \\
\hline 'Other' infectious diseases & 2144 & $3 \cdot 6$ & 95 & 1985 & $6 \cdot 2$ & 1616 \\
\hline Haematology/oncology & 2845 & $5 \cdot 1$ & 127 & 245 & $7 \cdot 2$ & 200 \\
\hline 'Other' problems & 1105 & $2 \cdot 0$ & 49 & 815 & $5 \cdot 1$ & 664 \\
\hline Neurology & 1306 & $2 \cdot 7$ & 58 & 304 & $5 \cdot 2$ & 248 \\
\hline Routine circumcision & 474 & 1.5 & 21 & 12 & $4 \cdot 0$ & 10 \\
\hline Eye disorders & 434 & $2 \cdot 0$ & 19 & 39 & $13 \cdot 0$ & 32 \\
\hline Renal problems & 436 & $4 \cdot 2$ & 19 & 481 & 6.9 & 21 \\
\hline Vaccine preventable diseases & 532 & $8 \cdot 3$ & 24 & 126 & $10 \cdot 5$ & 103 \\
\hline Mental disorders & 223 & $2 \cdot 9$ & 10 & 25 & $8 \cdot 3$ & 20 \\
\hline Endocrine/genetic diseases & 280 & $6 \cdot 0$ & 12 & 114 & $8 \cdot 0$ & 93 \\
\hline All categories & 52517 & $4 \cdot 4$ & 2339 & 22405 & $6 \cdot 5$ & 18245 \\
\hline
\end{tabular}

Table 5 Frequency of hospital admission for children up to the age of 2 years: Western Australia 1986 birth cohort. Excludes 62 records for 29 children of unknown race

\begin{tabular}{|c|c|c|c|c|}
\hline \multirow[b]{2}{*}{$\begin{array}{l}\text { Frequency of } \\
\text { admission }\end{array}$} & \multicolumn{2}{|c|}{ Non-Aboriginal } & \multicolumn{2}{|c|}{ Aboriginal } \\
\hline & $\begin{array}{l}\text { No of } \\
\text { children }\end{array}$ & $\begin{array}{l}\% \text { Of } \\
\text { cohort }\end{array}$ & $\begin{array}{l}\text { No of } \\
\text { children }\end{array}$ & $\begin{array}{l}\% \text { Of } \\
\text { cohon }\end{array}$ \\
\hline $\begin{array}{l}0 \\
1 \\
2 \\
3+\end{array}$ & $\begin{array}{r}15323 \\
4675 \\
1490 \\
968\end{array}$ & $\begin{array}{r}68 \\
21 \\
7 \\
4\end{array}$ & $\begin{array}{l}384 \\
243 \\
164 \\
437\end{array}$ & $\begin{array}{l}31 \\
20 \\
13 \\
36\end{array}$ \\
\hline Total cohort & 22456 & 100 & 1228 & 100 \\
\hline
\end{tabular}

births in the cohort, non-Aboriginal children spent 2339 days in hospital in the first two years of life compared with 18245 days for Aboriginal children. The mean length of stay for each admission was 4.4 days for nonAboriginal and 6.5 days for Aboriginal children. The mean number of days in hospital in the first two years or life for each child admitted (rather than for each 1000 live births) was 7.4 for non-Aboriginal and 26.5 for Aboriginal children (data not shown).

Table 5 shows the frequency of admissions for children in the first two years of life. Similar percentages of the non-Aboriginal and Aboriginal cohorts were admitted once only (21 and $20 \%$ respectively) but $4 \%$ of nonAboriginal children (accounting for $35 \%$ of all their admissions) and $36 \%$ of Aboriginal children (accounting for $83 \%$ of all their admissions) were admitted at least three times. Of those children with two or more admissions, about $10 \%$ of non-Aboriginal and $15 \%$ of Aboriginal children were likely to have been interhospital transfers for the same episode of disease (data not shown). We calculated these percentages by selecting all children who were discharged from one hospital and admitted to another on the same date and with the same clinically relevant category for the principal diagnosis.

Table 6 gives the number of different disease categories (principal diagnosis) which required hospital admission. Similar percentages of the non-Aboriginal and Aboriginal cohorts were in only one major disease category in the first two years of life ( 23 and $24 \%$ respectively), but $16 \%$ of Aboriginal children were in at least four categories, compared with $1 \%$ of nonAboriginal children.

\section{Discussion}

In this study we used record linkage between routinely collected data sets for the total

Table 6 Number of disease categories (principal diagnosis only) which required hospital admission: children up to the age of 2 years, Western Australia 1986 birth cohort. Excludes 62 records for 29 children of unknown race

\begin{tabular}{lcclcc}
\hline & \multicolumn{2}{l}{ Non-Aboriginal } & & \multicolumn{2}{l}{ Aboriginal } \\
\cline { 2 - 3 } \cline { 6 - 7 } No of categories & $\begin{array}{l}\text { No of } \\
\text { children }\end{array}$ & $\begin{array}{c}\text { \% Of } \\
\text { cohort }\end{array}$ & & $\begin{array}{l}\text { No of } \\
\text { children }\end{array}$ & $\begin{array}{c}\% \text { Of } \\
\text { cohort }\end{array}$ \\
\hline 0 & 15323 & 68 & & 384 & 31 \\
1 & 5185 & 23 & & 299 & 24 \\
2 & 1388 & 6 & & 212 & 17 \\
3 & 402 & 2 & & 140 & 11 \\
$4+$ & 158 & 1 & & 193 & 16 \\
Total cohort & 22456 & 100 & & 1228 & 100 \\
\hline
\end{tabular}


Western Australia population to describe the inpatient hospital morbidity of individual children as well as total hospital admissions. Our study confirms the continuing high rates of hospital admissions and the severity of the total burden of disease for Aboriginal children. ${ }^{7-11}$ For an adequate understanding of disease patterns and to enable appropriate health planning, it is important to relate admissions to hospital with the individual and with the population at risk. Although this is difficult to achieve for a total population, its value has been recognised by international ${ }^{31213}$ and Australian researchers. ${ }^{14} \mathrm{We}$ also consider that descriptive studies, if they are to be informative and useful, should be based on clinically relevant data and we have manipulated the available data to achieve this aim.

The classification of lower respiratory tract diseases differs between tables 1 and 2; table 2 (clinically relevant categories) includes other diseases of respiratory system, not elsewhere classified $^{6}$ in the category of upper respiratory tract diseases, whereas in table 1 (basic tabulation list) they are included in lower respiratory tract diseases. Validations of our database, including studying hospital records, have shown that these conditions were mostly minor respiratory ailments such as coughs and colds. Thus, using the basic tabulation list (table 1) overestimates lower respiratory tract disease and underestimates upper respiratory diseases.

Rates for perinatal disorders are lower in table 2 than table 1, especially for nonAboriginal children. This is because, from the point of view of clinical relevance, we have classified conditions such as bronchopulmonary dysplasia and respiratory distress syndrome as lower respiratory tract disease, while neonatal infections have been classified as other infectious diseases. Whichever of these two classifications is used, differences in the rates between Aboriginal and non-Aboriginal infants for perinatal conditions were not as great as for most other morbidities. Also, the mean length of stay for these conditions was the same for Aboriginal and non-Aboriginal infants, suggesting that the severity of perinatal morbidity was the same for the two groups. This is surprising given the downward shift in birth weight and gestational age distributions in Aboriginal compared with white infants, ${ }^{15}$ but it is consistent with recent patterns of infant mortality. Neonatal mortality for Aboriginal infants is similar to that for nonAboriginal infants, but postneonatal mortality remains three to four times higher for the former. ${ }^{16}$ In the USA differences between black and white infants for perinatal conditions were also less than expected. ${ }^{13}$

Whether we consider total hospital admissions or individual children admitted, the four most common conditions were the same for non-Aboriginal and Aboriginal children (gastrointestinal diseases, upper and lower respiratory tract diseases, and social admissions of healthy children), comprising $50 \%$ of all admissions for non-Aboriginal and $71 \%$ for Aboriginal children. The high rates for social admissions are notable and require further investigation. In our classification these were all healthy children who had been admitted as boarders accompanying sick people, or for reasons such as 'unspecified family circumstances'. Of the total admissions for nonAboriginal children, $11 \%$ were for social reasons; $12 \%$ for Aboriginal children. The data show that the high social admission rates were not due to repeated admissions for a small number of children as about 5\% (1144 children) of the non-Aboriginal and $24 \%$ (294 children) of the Aboriginal cohort had been admitted for social reasons.

The high social admission rate for Aboriginal children was expected ${ }^{10}$ but we were surprised that the rate for non-Aboriginal children was similar to that for gastrointestinal and lower respiratory tract diseases. The mean number of days for each admission for these three diagnostic categories for non-Aboriginal children was also similar, so that the total number of days spent in hospital per 1000 live births for the three categories was not very different. Given the high cost of a hospital bed and the possibility of nosocomial infections, it may be possible to implement cheaper and more appropriate care for these healthy children. Given the young age of the children and the size, diversity and isolation of Western Australia, however, detailed study of the reasons for these admissions, the geographical location, and the home background of the children is justified before any changes are suggested, as hospital care may be the only option in some circumstances.

Studies in other countries have also found high rates for social admissions for young children, ${ }^{417}$ though it is difficult to find studies which can be directly compared with our data. A study from New Zealand included a social reasons category defined as 'inadequate home environment', which included children who were admitted so that their mothers could be provided with guidance, as well as children admitted for other reasons. ${ }^{4}$ The children in the New Zealand study were aged up to 3 years and $2 \%$ of the cohort were admitted for inadequate home environment, comprising $11 \%$ of all admissions, the same proportion as in our study. In contrast with our study, however, it was concluded that the high rates were accounted for by repeat admissions (as they represented only $2 \%$ of the cohort). ${ }^{4} \mathrm{~A}$ study in Nottingham of consecutive emergency paediatric admissions, using data from 1975 to 1976 , found that more than $20 \%$ of children were admitted primarily for social reasons; these reasons included parental anxiety, inability to cope, and suspicion of child abuse. ${ }^{17} \mathrm{~A}$ repeat of this Nottingham study in 1985 showed that social admissions had decreased to $9 \%$ of total admissions, ${ }^{18}$ a similar proportion to that found in our study and the New Zealand study. ${ }^{4}$

The rates for non-Aboriginal and Aboriginal children for diseases which are currently nonpreventable (such as leukaemia and congenital anomalies) were similar, although the mean lengths of stay for each admission were higher for Aboriginal children. This was probably 
related to unsuitable home facilities and remoteness of home community being more likely among the Aboriginal children. ${ }^{10}$

The prevalence of hospital inpatient morbidity in this cohort of non-Aboriginal children was higher than for a cohort of Sheffield children born in $1985,{ }^{3}$ where $25 \%$ had been admitted to hospital by 2 years of age compared with $32 \%$ by two years of age in Western Australia. The Sheffield study found that almost $4 \%$ of the cohort were admitted three or more times compared with just over 4\% in Western Australia. Admission to hospital of children in Western Australia also appeared to be higher than that for the cohort of New Zealand children, where $29 \%$ had been admitted to hospital by 3 years of age. ${ }^{4}$ The New Zealand study ${ }^{4}$ had similar results with regard to the major categories for which children were admitted. Given the many reports advocating the minimisation of hospital stays for children, ${ }^{2}$ further investigations of our Western Australia data are justified to elucidate the specific risk factors for this higher rate of admission to hospital. Data from the Oxford record linkage study show that the mean total days spent in hospital in one year for children aged from 1 to 4 years ranged from $2 \cdot 2$ to 3.4 days, $^{2}$ compared with the result from our study of a mean of $7 \cdot 4$ days over two years for non-Aboriginal children admitted during the first two years of life.

These linked data have provided a unique picture of the inpatient hospital morbidity experienced by a total birth cohort during the first two years of life. Although we have been unable to include other childhood morbidity (such as outpatient and general practitioner visits), it is likely that the range of conditions found in this study reflects those found in the general community. ${ }^{4} \mathrm{We}$ are confident that we have described all the serious morbidity experienced by the cohort children. Aboriginal children, however, may be more seriously ill than non-Aboriginal children before they are admitted to hospital. ${ }^{19}$

This descriptive paper is the first step in a series of studies investigating admissions to hospital for all children in Western Australia. Using these linked data we will be able to ascertain risk factors for particular morbidities and target specific areas where improvements in healthcare and hospital costs could be made. The inclusion of social, demographic, and economic data on our database allows us to include these important factors ${ }^{1720}$ in analytical studies. For example, we can investigate antenatal risk factors for low birthweight infants and preterm birth, including indicators of socioeconomic status, and we can follow up these children to determine their subsequent morbidity. Such longitudinal studies will give us an increased understanding of the burden of childhood morbidity and enable us to aim preventive measures at those children in most need.

The Health Department of Western Australia provided access to data and we thank them for their cooperation. We also thank Dr Peter Sly and Dr William Macdonald for their assistance, particularly with the development of the clinically relevan categories. Anne Read was supported by a grant from the
National Health and Medical Research Council, Patricia Morich by The Wellcome Trust, and John Gibbins by the Western Australia Health Promotion Foundation.

1 Goldacre MJ, Simmons H. Henderson J, Gill LE. Trends in episode based and person based rates of admission to hospital in the Oxford record linkage study area. $B M F$ 1988; 296: 583-5.

2 Henderson J, Goldacre MJ, Fairweather J, et al. Time spent in hospital by children as a health care indicator: inter-district comparisons. $\mathcal{f}$ Public Health Med 1992; 14: 35-8.

3 Spencer NJ, Lewis MA. Multiple admissions under 2 years of age. Arch Dis Child 1991; 66: 938-40.

4 Fergusson DM, Beautrais AL, Harwood LJ, Shannon FT. The prevalence of illness in a birth cohort. New Zealand Medical fournal 1992; 95: 6-10.

5 Gee V. Perinatal statistics in Western Australia: ninth annual report of the Western Australian Midwives' Notification system 1991. Perth: Health Department of Western Australia, 1992.

6 World Health Organisation. Manual of the international statistical classification of diseases, injuries and causes of death. 9th Revision. Geneva: WHO, 1977.

7 Forbes DA, Williams EJB, Macdonald WB. Morbidity patterns of Aboriginal and non-Aboriginal children patterns of Aboriginal and non-Aboriginal children admitted

8 McNeilly J, Cicchin C, Oliver D, Gracey M. Infectious disease in Aboriginal infants and children in Western Australia. Med f Aust 1983; 2: 547-51.

9 Dibley $M$, Waddell $C$. Length of hospitalisation of Aboriginal and non-Aboriginal children in Western Australia, 1971-1979. Med $\mathscr{f}$ Aust 1983; 1: 59-63.

10 Waddell C, Dibley M. The medicalization of Aboriginal children: a comparison of the lengths of hospital-stay of Aboriginal and non-Aboriginal children in Western Australia and the Northern Territory. Australian Paediatric fournal 1986; 22: 27-30.

11 Gracey M, Anderson CM. Hospital admissions for infections of Aboriginal and non-Aboriginal infants and tions of Aboriginal and non-Aboriginal infants and Paediatric fournal 1989; 25: 230-5.

12 Starfield B. Childhood morbidity: comparisons, clusters and trends. Pediatrics 1991; 88: 519-26.

13 Becerra JE, Fry YW, Rawley DL. Morbidity estimates of conditions originating in the perinatal period: United States, 1986 through 1987. Pediatrics 1991; 88: 553-9.

14 Munoz E, Powers JR, Mathews JD. Hospitalisation patterns in children from 10 Aboriginal communities in the Northern Territory. Med f Aust 1992; 156: 524-8.

15 Kliewer EV, Stanley FJ. Aboriginal and white births in Australia, 1980-1986. Med f Aust 1989; 151: 493-502.

16 Gee V. The 1990 Western Australian birth cohort - perinatal and infant mortality identified by maternal race. Perth: Health Department of Western Australia, 1992.

17 Wynne J, Hull D. Why are children admitted to hospital? $B M \mathcal{F}$ 1977; ii: 1140-2.

18 Hutchison TP, Durojaiye L, Madeley RJ. Improved primary care does not prevent the admission of children to hospital [Abstract]. Arch Dis Child 1987; 62: 649-50.

19 Yusuf F, Hamilton A. Hospital morbidity among Aboriginal Australians in New South Wales. F Biosoc Sci 1982; 14: 445-63.

20 Egbuonu L, Starfield B. Child health and social status. Pediatrics 1982, 69: 550-7.

\section{Appendix}

\section{SUMMARY OF CLINICALLY RELEVANT CATEGORIES}

ICD9 codes (principal diagnosis): examples of codes in each category (full list available from authors)

\section{ICD9 code Condition}

Upper respiratory tract diseases

3810-3829 Otitis media

4639 Acute tonsillitis

$4644 \quad$ Croup

4659 Upper respiratory tract infection

5198 Other diseases of the respiratory system, not classified elsewhere

Gastrointestinal diseases

0091 Colitis, enteritis, and gastroenteritis of presumed infectious origin

0093 Diarrhoea, of presumed infectious origin

2765 Volume depletion

5589 Non-infective gastroenteritis and colitis

7793 Feeding problems in newborn infants

7833 Feeding difficulties and

$7834 \quad$ mismanagement

Lower respiratory tract diseases

4660 Bronchitis

$4661 \quad$ Bronchiolitis

4860, 4869 Pneumonia

4930, 4939 Asthma 


\begin{tabular}{|c|c|c|c|}
\hline 7699 & $\begin{array}{l}\text { Respiratory distress syndrome } \\
\text { including hyaline membrane disease }\end{array}$ & $\begin{array}{l}2809 \\
7730-7735\end{array}$ & $\begin{array}{l}\text { Iron deficiency anaemia } \\
\text { Haemolytic disease of fetus or new }\end{array}$ \\
\hline 7707 & Bronchopulmonary dysplasia & $7740-7747$ & Perinatal jaundice \\
\hline 7708 & Other respiratory problems originating & \multicolumn{2}{|c|}{ 'Other' problems } \\
\hline & in the perinatal period & 5210 & Dental caries \\
\hline \multicolumn{2}{|c|}{ Social admissions (healthy children) } & 6910 & Napkin rash \\
\hline V201 & Other healthy infant receiving care & 7806 & Pyrexia of unknown origin \\
\hline V605 & Holiday relief care & 7807 & Malaise and fatigue \\
\hline V612 & Parent-child problems & 7860 & Dyspnoea and respiratory \\
\hline V619 & Unspecified family circumstances & & abnormalities \\
\hline V641 & $\begin{array}{l}\text { Waiting for surgical/other procedure } \\
\text { not carried out }\end{array}$ & $\begin{array}{l}\text { Neurology } \\
3420-3449\end{array}$ & Cerebral palsy \\
\hline V650 & $\begin{array}{l}\text { Healthy person (boarder) accompanying } \\
\text { sick person }\end{array}$ & $\begin{array}{l}3450-3459 \\
3890-3899\end{array}$ & $\begin{array}{l}\text { Epilepsy } \\
\text { Deafness }\end{array}$ \\
\hline Congenital an & malies & 7790 & Convulsions in newborn \\
\hline $5500-5532$ & Congenital hernia & 7803 & Convulsions \\
\hline 6050 & Congenital phimosis & \multirow{2}{*}{\multicolumn{2}{|c|}{ Routine circumcision }} \\
\hline $7400-7599$ & Congenital anomalies & & Routine or ritual circt \\
\hline \multicolumn{2}{|c|}{ Perinatal conditions } & \multirow{2}{*}{ V502, V508 } & absence of si \\
\hline 7634 & Morbidity from caesarean delivery & & indication \\
\hline $\begin{array}{l}7651 \\
7685\end{array}$ & $\begin{array}{l}\text { Preterm infant } \\
\text { Severe birth asphyxia }\end{array}$ & \multirow{2}{*}{$\begin{array}{l}\text { Eye disorders } \\
3755\end{array}$} & \\
\hline \multicolumn{2}{|c|}{ Trauma, accidents, poisoning } & & Stenosis and insufficiency of lacrimal \\
\hline $7180-7199$ & Derangement of joints & $3780-3789$ & $\begin{array}{l}\text { passages } \\
\text { Strabismus }\end{array}$ \\
\hline $8000-9299$ & Fractures, other injuries & \multicolumn{2}{|c|}{ Renal problems } \\
\hline $9400-9499$ & Burns & 5859 & Chronic renal failure \\
\hline $0-9899$ & Poisoning & 5990 & $\begin{array}{l}\text { Chronic renal faulure } \\
\text { Urinary tract infection }\end{array}$ \\
\hline $\begin{array}{l}9941 \\
9955\end{array}$ & atal submersion & $5930-5939$ & Disorders of kidney and ureter \\
\hline \multicolumn{2}{|c|}{ 'Other' infectious diseases } & \multicolumn{2}{|c|}{ Vaccine preventable diseases } \\
\hline 0529 & Chickenpox & 0330-0339 & Whooping cough \\
\hline 0542 & Herpetic gingivostomatitis & $0550-0559$ & Measles \\
\hline 0799 & Unspecified viral infection & 0569 & Rubella \\
\hline 1330 & Scabies & \multicolumn{2}{|c|}{ Mental disorders } \\
\hline 3720 & Acute conjunctivitis & 3131 & Emotional disturbance, with misery \\
\hline $7711-7718$ & Infections specific to the perinatal & & and unhappin \\
\hline & period & \multicolumn{2}{|c|}{ Endocrine/genetic diseases } \\
\hline \multicolumn{2}{|c|}{ Haematology/oncology } & 2500 & Diabetes mellitus \\
\hline 1952 & Malignant neoplasm of abdomen & 2770 & Cystic fibrosis \\
\hline 20 & Acute lymphoid leukaemia & $2790-2799$ & Disorders involving the immune \\
\hline & Haemangioma and lymphangioma & & mechanism \\
\hline
\end{tabular}

